\title{
Neural Substrates Mediating Human Delay and Trace Fear Conditioning
}

\author{
David C. Knight, ${ }^{1}$ Dominic T. Cheng, ${ }^{1}$ Christine N. Smith, ${ }^{1}$ Elliot A. Stein, ${ }^{2}$ and Fred J. Helmstetter ${ }^{1,2}$ \\ ${ }^{1}$ Department of Psychology, University of Wisconsin-Milwaukee, Milwaukee, Wisconsin 53201, and ${ }^{2}$ Department of Psychiatry, Medical College of \\ Wisconsin, Milwaukee, Wisconsin 53226
}

Previous functional magnetic resonance imaging (fMRI) studies with human subjects have explored the neural substrates involved in forming associations in Pavlovian fear conditioning. Most of these studies used delay procedures, in which the conditioned stimulus (CS) and unconditioned stimulus (UCS) coterminate. Less is known about brain regions that support trace conditioning, a procedure in which an interval of time (trace interval) elapses between CS termination and UCS onset. Previous work suggests significant overlap in the neural circuitry supporting delay and trace fear conditioning, although trace conditioning requires recruitment of additional brain regions. In the present event-related fMRI study, skin conductance and continuous measures of UCS expectancy were recorded concurrently with whole-brain blood oxygenation level-dependent (BOLD) imaging during direct comparison of delay and trace discrimination learning. Significant activation was observed within the visual cortex for all CSs. Anterior cingulate and medial thalamic activity reflected associative learning common to both delay and trace procedures. Activations within the supplementary motor area (SMA), frontal operculum, middle frontal gyri, and inferior parietal lobule were specifically associated with trace interval processing. The hippocampus displayed BOLD signal increases early in training during all conditions; however, differences were observed in hippocampal response magnitude related to the accuracy of predicting UCS presentations. These results demonstrate overlapping patterns of activation within the anterior cingulate, medial thalamus, and visual cortex during delay and trace procedures, with additional recruitment of the hippocampus, SMA, frontal operculum, middle frontal gyrus, and inferior parietal lobule during trace conditioning. These data suggest that the hippocampus codes temporal information during trace conditioning, whereas brain regions supporting working memory processes maintain the CS-UCS representation during the trace interval.

Key words: Pavlovian conditioning; delay conditioning; trace conditioning; learning and memory; fMRI; hippocampus; emotion; deactivation

\section{Introduction}

In Pavlovian fear conditioning, presentation of a conditioned stimulus (CS) typically predicts an aversive outcome such as shock. Expression of a conditioned response (CR) to the CS alone is taken as evidence that an association between the CS and the unconditioned stimulus (UCS) has been learned. Delay and trace procedures differ in the temporal relationship specified between the CS and UCS. In delay conditioning, the CS and UCS normally coterminate, whereas in trace conditioning an interval of time passes between CS termination and UCS onset (Rescorla, 1988).

Much of what is known about the neurobiology of fear conditioning comes from investigations in laboratory animals. The thalamus, amygdala, hippocampus, and sensory cortex each con-

Received Feb. 14, 2003; revised 0ct. 9, 2003; accepted Nov. 5, 2003.

This work was supported by National Institutes of Health (NIH) Grants MH060668 and DA09465, NIH Fellowship MH11722, and the McDonnell-Pew Foundation. We thank Dr. Tom Ross for statistical and technical advice.

Correspondence should be addressed to Dr. Fred J. Helmstetter, Department of Psychology, University of Wisconsin-Milwaukee, P.0. Box 413, Milwaukee, WI 53201. E-mail: fjh@uwm.edu.

D. C. Knight's present address: Laboratory of Brain and Cognition, National Institute of Mental Health, Bethesda, MD 20892.

E. A. Stein's present address: Neuroimaging Research Branch, National Institute on Drug Abuse-Intramural Research Program, Baltimore, MD 21230.

DOI:10.1523/JNEUROSCI.0433-03.2004

Copyright $\odot 2004$ Society for Neuroscience $\quad 0270-6474 / 04 / 240218-11 \$ 15.00 / 0$ tribute to the acquisition and expression of learned fear (LeDoux, 1995, 2000; Davis, 2000; Maren, 2001). Although there is significant overlap in the neural circuitry supporting delay and trace conditioning, the latter requires participation of additional brain regions such as the hippocampus for successful learning. Hippocampal cells are active during both delay and trace conditioning trials, but this activity appears to be critical only for performance of trace CRs (Berger et al., 1983; Solomon et al., 1986; Moyer et al., 1990; Weiss et al., 1996; McEchron et al., 1997, 1998).

Several suggestions have been offered regarding the specific functions of the hippocampus during trace conditioning. The hippocampus may encode temporal information regarding event durations (CS and UCS), temporal relationships between events (interstimulus interval and trace interval), and CR timing (James et al., 1987; Cole et al., 1995; Rodriguez and Levy, 2001). For example, hippocampal lesions can disrupt CR timing, but they do not necessarily abolish the CR altogether (James et al., 1987). Another possibility is that awareness is important for trace conditioning and is established through hippocampal-dependent processes. Several studies show a correlation between declarative memory performance and the ability to learn trace CRs, whereas delay conditioning can occur without awareness of stimulus re- 
lationships (McGlinchey-Berroth et al., 1997; Clark and Squire, 1998; Carter et al., 2003). Concurrent measures of awareness should provide a more accurate estimation of when subjects become aware of experimental contingencies as well as their degree of awareness at any given time than frequently used questionnaire-based methods (LaBar and Disterhoft, 1998; Lovibond and Shanks, 2002).

Imaging studies examining neural activity during delay fear conditioning in humans have reported learning-related changes within sensory cortices, anterior cingulate cortex (AC), insula, amygdala, hippocampus, and medial thalamus (Hugdahl et al., 1995; Wik et al., 1996; Buchel et al., 1998; LaBar et al., 1998; Knight et al., 1999; Cheng et al., 2003). Buchel et al. (1999) observed responses to a trace CS within the AC, insula, amygdala, and hippocampus. To date, however, no direct delay versus trace conditioning comparisons have been examined, leaving open such questions as whether the trace activity described actually differs in a meaningful way from that seen previously in delay conditioning. The present study was designed to determine regions of activation unique to trace interval processing during trace conditioning, with special emphasis on understanding the role of the hippocampus.

\section{Materials and Methods \\ Procedure}

Seventeen healthy, right-handed volunteers (nine female; mean age, $23 \pm 6$; range, $18-43$ years) gave informed consent and participated in this study, which was approved by the institutional review boards of the University of Wisconsin-Milwaukee and the Medical College of Wisconsin. Subjects were presented four blocks (15 trials per block) of the CSs while blood oxygenation level-dependent (BOLD)-weighted functional images were obtained. The CS + and UCS presentations coterminated on all stimulus blocks. The $\mathrm{CS}_{10}$ was followed by a $10 \mathrm{sec}$ trace interval before UCS presentation. The CS - was presented alone (see Fig. $1 A$ ).

\section{Apparatus}

Magnetic resonance imaging. Whole-brain imaging was performed on a 3 Tesla/60 Bruker Biospec scanner using a multislice gradient-echo echoplanar pulse sequence. Contiguous $8 \mathrm{~mm}$ sagittal slices were collected (repetition time $=2000 \mathrm{msec}$; echo time $=27.2 \mathrm{msec}$; field of view $=24$ $\mathrm{cm}$; flip angle $=90^{\circ}$ ) in a series of 340 sequential images (for a total of 680 sec) during each block of stimulus presentations. High-resolution anatomical images were obtained with a three-dimensional multiplanar inversion recovery gradient-echo imaging sequence to serve as an anatomical map over which functional images were superimposed.

Electrical stimulus. A customized AC $(60 \mathrm{~Hz})$ shock generator provided $500 \mathrm{msec}$ transcutaneous electrical stimulation of the right tibial nerve behind the medial malleolus through two aluminum surface electrodes $\left(2 \mathrm{~cm}^{2}\right.$ area) that were held in place by Velcro straps wrapped around the subject's ankle. Stimulus intensity was set for each subject individually by asking participants to rate the intensity of stimuli during practice trials from 0 to $5(0=$ no sensation; $5=$ painful, but tolerable $)$. The intensity of the first practice trial was equal to $0 \mathrm{~mA}$ and was increased gradually, interspersed with two declinations in stimulus intensity, until the subject rated the stimulation as a 5 or the stimulus intensity reached the cutoff current of $7.35 \mathrm{~mA}$. This tailored electrical stimulus was maintained at a constant intensity for each subject throughout the experiment.

Visual stimuli. Five trials of three distinct conditioned stimuli (CS+, $\mathrm{CS}_{10}$, and CS - ) varying in shape, number, and color (one blue circle, two yellow triangles, and three red squares; $10 \mathrm{sec}$ duration; $30 \mathrm{sec}$ intertrial interval) were presented during each stimulus block. Conditioned stimuli were counterbalanced and presented in a pseudorandom order so that no more than two trials of the same CS were presented consecutively. The image was projected (Epson model ELP 5000) to a back-illuminated screen $\left(60 \times 60 \mathrm{~cm}\right.$; field of view $=20^{\circ}$ horizontal $\times 18^{\circ}$ vertical $)$ located at the subject's feet and viewed through a set of prismatic glasses attached to the radio frequency birdcage coil.
Skin conductance response. Skin conductance response (SCR) was measured $(250 \mathrm{~Hz})$ with a pair of surface gel cup electrodes (silver/silver chloride; $8 \mathrm{~mm}$ diameter; Biopac model EL200 sec) attached, $2 \mathrm{~cm}$ apart, to the sole of the subject's left foot.

Shock expectancy. A rotary dial was used during the scanning session to monitor subjects' expectancy of receiving the electrical stimulation. Subjects were instructed to move the dial with their right hand to control a rating bar presented at the bottom of the visual display throughout each scanning block.

Before scanning, subjects were trained in the use of the dial and rating bar to reduce the effects of motor learning on behavioral measures. Subjects were directed to rate their shock expectancy (SE) on a continuous scale from 0 to $100(0=$ certain that the electrical stimulus will not be presented; $50=$ uncertain whether the electrical stimulus will be presented; $100=$ certain that the electrical stimulus will be presented). Participants were instructed to continuously update their rating to accurately reflect their current SE. SE data were sampled at $250 \mathrm{~Hz}$ throughout each training block.

\section{Data analysis}

Behavioral and functional magnetic imaging (fMRI) data were analyzed as a function of the four stimulus periods: the three $10 \mathrm{sec}$ duration CS periods (CS+, $\mathrm{CS}_{10}$, and CS - ) and the 10 sec trace interval. The $\mathrm{CS}_{10}$ and trace interval were analyzed separately to equate the duration of all stimulus periods compared. In the remaining sections, $\mathrm{CS}_{10}$ refers only to the CS period of the $\mathrm{CS}_{10}$, whereas the period of time between termination of the CS period of the $\mathrm{CS}_{10}$ and onset of the UCS is referred to as the trace interval.

Pain rating. Pain ratings were obtained after each training block of the scanning session. Subjects were instructed to rate electrical stimulus presentations from the preceding trial block on the same five-point scale used during pre-scan training.

Skin conductance response. Skin conductance response (SCR) was calculated by subtracting the average skin conductance measurement during the baseline period (the $10 \mathrm{sec}$ immediately preceding CS presentations) from the second interval response (the peak response during the 5 sec preceding termination of the $\mathrm{CS}+, \mathrm{CS}-, \mathrm{CS}_{10}$, or trace interval). The second interval response is generally considered an emotional response elicited by UCS anticipation and is considered an accurate reflection of learning the CS-UCS association (Prokasy and Raskin, 1973; Wolter and Lachnit, 1993).

Shock expectancy. SE was defined as the peak response during the $\mathrm{CS}+$, $\mathrm{CS}-, \mathrm{CS}_{10}$, and trace interval.

fMRI. fMRI data processing was conducted with AFNI software version 2.28 (Cox and Hyde, 1997). Three-dimensional motion correction and edge-detection algorithms were applied to all functional data (Cox and Jesmanowicz, 1999). Subjects whose fMRI time series had perceptible, residual head movements based on cinematic viewing were excluded from further analysis.

fMRI time series data were analyzed using a multiple regression strategy that used the measured fMRI signal and input reference functions representing the temporal location of the $\mathrm{CS}+, \mathrm{CS}-, \mathrm{CS}_{10}$, and trace interval to estimate the impulse response functions evoked by stimulus presentations. The percentage of area under the response curve (AUC) was used as a measure of the strength of response evoked by each stimulus period. Functional maps reflecting the AUC during the CS+, CS-, $\mathrm{CS}_{10}$, and trace interval were converted to a standard stereotaxic coordinate system (Talairach and Tournoux, 1988) and spatially blurred using a $4 \mathrm{~mm}$ full-width at half-maximum isotropic Gaussian filter. Repeatedmeasures ANOVA against the null hypothesis of no effect were performed voxel by voxel on the AUC across the four training blocks for each of the four stimulus intervals. A significance level of $p<0.005$ along with the exclusion of clusters of voxels with volumes $<225 \mathrm{~mm}^{3}$ were used to threshold data. Volumes of active tissue passing this threshold were selected as functional regions of interest (ROIs). ANOVA and post hoc analyses comparing responses elicited by each stimulus period (CS + , $\mathrm{CS}-, \mathrm{CS}_{10}$, and trace interval) across the four training blocks were performed on the average response from all voxels within an ROI. 
A
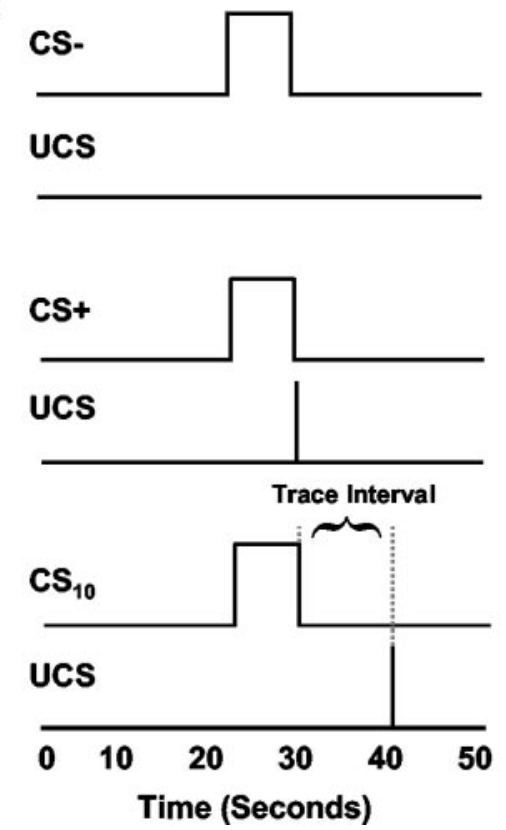

B

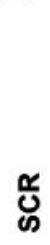

Block 1
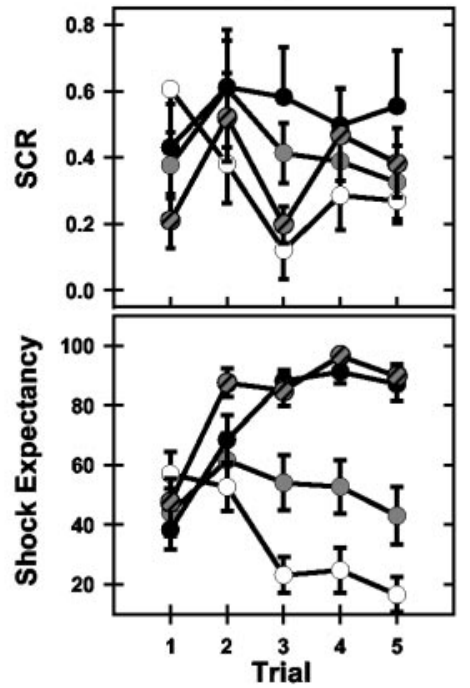

CS+

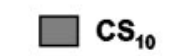

Figure 1. Experimental design and behavioral data. $A$, Illustration of the experimental design. Participants were exposed to three visual CSs and brief electrical stimulation (UCS) over four blocks of trials. One CS was always followed by the UCS (CS +), one was separated from the UCS by a 10 sectrace interval ( $\left(S_{10}\right.$ ), and one was never followed by the UCS (CS - ). B, SCR (top graphs) and shock expectancy (bottom graphs) were recorded concurrently with fMRI. Learning-related differences in responding developed within the first training block (left graphs) and were maintained across the training session (right graphs).

\section{Results}

\section{Behavioral data}

Electrical stimulation and pain ratings

Electrical stimulus intensities averaged $3.17 \pm 0.62 \mathrm{~mA}$ (range, 0.84-7.35 mA). A 1 (pain rating) $\times 4$ (block) repeated-measures ANOVA revealed that pain ratings decreased across the four training blocks from $4.21 \pm 0.22$ to $3.47 \pm 0.27\left(F_{(3,48)}=10.36\right.$; $p<0.05)$.

\section{Skin conductance response}

ANOVA revealed that differential SCRs developed within the four stimulus periods across trials of block 1 (stimulus period main effect: $F_{(3,48)}=10.99, p<0.05$; stimulus period by trial interaction: $\left.F_{(12,192)}=7.81, p<0.05\right)$. CS + presentations evoked larger SCRs on block 1 compared with the CS $-(t=2.97 ; p<$ $0.05), \mathrm{CS}_{10}(t=2.43 ; p<0.05)$, and trace interval $(t=2.54 ; p<$ $0.05)$. An intermediate level of conditioned responding was observed during the $\mathrm{CS}_{10}$. These responses were larger than those evoked by CS $-(t=1.90 ; p<0.05)$ but did not differ from trace interval responses. Repeated-measures ANOVA on SCR data across the four blocks of training revealed differential conditioned responses developed during block 1 and were maintained across all four training blocks (stimulus period main effect: $F_{(3,48)}=$ $7.76 ; p<0.05)$, with larger SCRs to presentations of the CS+ $(t=2.73 ; p<0.05)$ and $\mathrm{CS}_{10}(t=2.18 ; p<0.05)$ compared with the CS - . Trace interval responses did not differ from those elicited by other stimulus periods (Fig. $1 B$ ).

\section{Shock expectancy}

Participant expectations of UCS presentation differentially developed to CS presentations within the first training block, as evidenced by a significant main effect for stimulus period $\left(F_{(3,48)}=\right.$ 63.94; $p<0.05)$ and a significant stimulus period by trial interaction $\left(F_{(12,192)}=48.47 ; p<0.05\right)$. Post hoc comparisons revealed higher SE during presentations of the CS $+(t=6.29 ; p<$
$0.05), \mathrm{CS}_{10}(t=3.07 ; p<0.05)$, and trace interval $(t=8.12 ; p<$ $0.05)$ compared with the CS - . Furthermore, SE was greater during CS + trials $(t=3.55 ; p<0.05)$ and the trace interval $(t=4.73$; $p<0.05)$ than during the $\mathrm{CS}_{10}$. Additionally, shock expectancies were greater during the trace interval than during $\mathrm{CS}+$ trials $(t=$ 2.15; $p<0.05)$. Repeated-measures ANOVA on SE data for the four stimulus periods across the four training blocks revealed that differential responses to CS presentations were maintained across all training blocks (stimulus period main effect: $F_{(3,48)}=279.02$; $p<0.05)$ with higher SE to presentations of the CS+ $(t=$ 11.26; $p<0.05), \mathrm{CS}_{10}(t=3.64 ; p<0.05)$, and trace interval $(t=15.12 ; p<0.05)$ compared with the CS - . Greater shock expectancies were seen during CS + trials $(t=6.55 ; p<0.05)$ and the trace interval $(t=8.02 ; p<0.05)$ compared with the $\mathrm{CS}_{10}$ throughout training, as were the larger shock expectancies during the trace interval $(t=2.14 ; p<0.05)$ compared with $\mathrm{CS}+$ trials (Fig. $1 B$ ).

\section{fMRI data}

Regions of interest

A number of discrete areas of activation met criteria for inclusion as ROIs and are presented in Tables 1 and 2. Imaging results are first discussed for regions characterized by an increase in fMRI signal intensity during all CS presentations. These activations appeared to be linked specifically to presentation of visual stimuli and were localized within the visual cortex. In the second section, data from regions in which delay $(\mathrm{CS}+)$ and trace $\left(\mathrm{CS}_{10}\right.$ or trace interval) conditioning evoked a larger AUC than CS - trials are presented. These regions are presumably involved in forming CS-UCS associations and are characterized by two separate patterns of activation: (1) ROIs in which delay and trace conditioning elicited similar response amplitudes that were larger than $\mathrm{CS}$ - responses and (2) ROIs in which the delay trials evoked the largest response, trace conditioning trials elicited an intermediate 
Table 1. Differential activity evoked by the $\mathrm{CS}_{+}, \mathrm{CS}_{10}$, trace interval, and $\mathrm{CS}-$

\begin{tabular}{|c|c|c|c|c|c|c|}
\hline \multirow[b]{2}{*}{ Anatomic label } & \multirow[b]{2}{*}{ Hemisphere } & \multirow[b]{2}{*}{ Brodmann area } & \multirow[b]{2}{*}{ Volume $\left(\mathrm{mm}^{3}\right)$} & \multicolumn{3}{|l|}{ CM } \\
\hline & & & & $\mathrm{RL}$ & AP & IS \\
\hline \multicolumn{7}{|l|}{ Frontal } \\
\hline Supplementary motor area & Right & 6 & 5263 & 3 & -4 & 60 \\
\hline Middle frontal gyrus & Right & 9 & 992 & 31 & 39 & 35 \\
\hline Middle frontal gyrus & Left & $9 / 46$ & 477 & -34 & 39 & 28 \\
\hline Frontal operculum & Right & $6 / 44$ & 2458 & 44 & 9 & 7 \\
\hline Frontal operculum & Left & $6 / 44$ & 749 & -47 & 5 & 6 \\
\hline Anterior cingulate & Bilateral & 32 & 1063 & 2 & 15 & 40 \\
\hline \multicolumn{7}{|l|}{ Parietal } \\
\hline Inferior parietal lobule & Right & 40 & 2869 & 53 & -48 & 40 \\
\hline Supramarginal gyrus & Left & 40 & 419 & -40 & -47 & 33 \\
\hline \multicolumn{7}{|l|}{ Occipital } \\
\hline Middle occipital gyrus & Left & 19 & 1443 & -25 & -85 & 14 \\
\hline Middle occipital gyrus & Right & 19 & 321 & 29 & -84 & 15 \\
\hline Lingual gyrus & Right & $18 / 19$ & 976 & 19 & -82 & -11 \\
\hline Lingual gyrus & Left & $18 / 19$ & 6280 & -29 & -57 & -13 \\
\hline \multicolumn{7}{|l|}{ Subcortical } \\
\hline Medial thalamus & Left & & 1038 & -8 & -19 & 10 \\
\hline Medial thalamus & Right & & 294 & 6 & -19 & 10 \\
\hline Hippocampus & Left & & 480 & -27 & -14 & -14 \\
\hline
\end{tabular}

Locations and volumes of statistically significant $(p<0.005)$ contiguous activation $>215 \mathrm{~mm}^{3}$. The Brodmann area and Talairach coordinates (Talairach and Tournoux, 1988) are provided for the centers-of-mass $(C M)$ of contiguous activation. RL, Right/left; AP, anterior/posterior; IS, inferior/superior.

Table 2. Regions showing task-induced deactivation

\begin{tabular}{|c|c|c|c|c|c|c|}
\hline \multirow[b]{2}{*}{ Anatomic label } & \multirow[b]{2}{*}{ Hemisphere } & \multirow[b]{2}{*}{ Brodmann area } & \multirow[b]{2}{*}{ Volume $\left(\mathrm{mm}^{3}\right)$} & \multicolumn{3}{|l|}{$C M$} \\
\hline & & & & RL & AP & IS \\
\hline Superior frontal gyrus & Left & 8 & 2434 & -22 & 20 & 48 \\
\hline Inferior frontal gyrus & Left & 44 & 466 & -35 & 5 & 33 \\
\hline Anterior cingulate & Bilateral & $24 / 32$ & 1734 & -1 & 48 & 6 \\
\hline Posterior cingulate & Bilateral & $23 / 31$ & 27,920 & -1 & -56 & 24 \\
\hline Superior temporal gyrus & Left & 39 & 544 & -50 & -59 & 20 \\
\hline Middle temporal gyrus & Right & 21 & 433 & 54 & -8 & -7 \\
\hline Postcentral gyrus & Right & 3 & 689 & 26 & -29 & 65 \\
\hline
\end{tabular}

Locations and volumes of statistically significant $(p<0.005)$ contiguous deactivation $>215 \mathrm{~mm}^{3}$. The Brodmann area and Talairach coordinates (Talairach and Tournoux, 1988) are provided for the centers-of-mass (CM) of contiguous activation.

level response, and the CS - provoked the smallest response. In the third section, imaging results are shown for regions characterized by large fMRI signal intensities during the trace interval. These activations appeared to be involved specifically in trace interval processing. The fourth section details ROIs in which a pattern of deactivation was observed. This deactivation may reflect the interruption of resting state processes by task performance. In the final section, hippocampal results are described.

Visual cortex activity

Four ROIs, bilateral lingual (right: $F_{(3,48)}=17.30, p<0.001$; left: $F_{(3,48)}=26.07, p<0.0001$ ), and middle occipital gyri (right: $F_{(3,48)}=17.52, p<0.001$; left: $\left.F_{(3,48)}=18.74, p<0.001\right)$ within the visual cortex showed larger responses to presentations of all CSs $\left(\mathrm{CS}-, \mathrm{CS}+\right.$, and $\left.\mathrm{CS}_{10}\right)$ than the trace interval. In addition, middle occipital gyrus responses were larger during the CS+ bilaterally (right: $t=2.19, p<0.0215$; left: $t=2.50, p<0.012$ ) and $\mathrm{CS}_{10}$ within the right hemisphere (right: $t=3.02, p<0.004$; left: $t<1.00$ ) than to CS - trials.

In summary, visually evoked activations identified within bilateral lingual and middle occipital gyri were characterized by increased fMRI signal during CS presentations ( $\mathrm{CS}-, \mathrm{CS}+$, and $\mathrm{CS}_{10}$ ) relative to the trace interval. Over training, larger responses developed to $\mathrm{CS}+$ and $\mathrm{CS}_{10}$ compared with $\mathrm{CS}-$ trials within the middle occipital gyrus. The development of such activity may reflect altered sensory processing of stimuli that gain biological or emotional significance (i.e., stimuli that predict the UCS). Simi- lar results have been reported previously (Knight et al., 1999; Cheng et al., 2003).

\section{Delay and trace activity}

Figure $2 A$ presents ROIs in which delay $(\mathrm{CS}+)$ and trace $\left(\mathrm{CS}_{10}\right.$ or trace interval) trials evoked a larger AUC than CS - trials. Regions with two separate patterns of activation are included in this category: (1) ROIs in which delay and trace conditioning trials elicited similar response amplitudes that were larger than CSresponses and (2) ROIs in which delay trials evoked the largest response, trace trials elicited an intermediate level response, and the CS - provoked the smallest response. These regions include the $\operatorname{AC~}\left(F_{(3,48)}=21.37 ; p<0.0001\right)$, bilateral medial thalamus $\left(\right.$ right: $F_{(3,48)}=17.21, p<0.001$; left: $\left.F_{(3,48)}=33.03, p<0.0001\right)$, and left supramarginal gyrus $\left(F_{(3,48)}=17.89 ; p<0.001\right)$. The average fMRI time course for trace, delay, and CS - responses within these ROIs are presented in Figure 3.

Within the AC, the CS+ $(t=3.38 ; p<0.002), \mathrm{CS}_{10}(t=4.27$; $p<0.0005)$, and trace interval $(t=4.05 ; p<0.0005)$ elicited larger responses than the $\mathrm{CS}-$. Trace interval responses were larger than responses to the $\mathrm{CS}_{10}(t=2.35 ; p<0.016)$ but were not different from $\mathrm{CS}+$ evoked responses. A significant stimulus period by block interaction was seen $\left(F_{(9,144)}=8.80 ; p<0.009\right)$ (see Fig. 5) with similar responses to the CS+, trace interval, and $\mathrm{CS}-$ on block 1 , and greater responding to the CS $+(t=3.01$, $p<0.004)$ and trace interval $(t=3.45, p<0.0015)$ compared with CS - trials on block 4 of training. 
Post hoc comparisons of medial thalamic activity revealed larger responses during the CS+ (right: $t=3.48, p<$ 0.0015; left: $t=3.81, p<0.001), \mathrm{CS}_{10}$ (right: $t=3.82, p<0.001$; left: $t=4.30$, $p<0.0005$ ), and trace interval (right: $t=$ 3.02, $p<0.004$; left: $t=2.06, p<0.028$ ) compared with CS - presentations. AUC was greater during the $\mathrm{CS}+$ than $\mathrm{CS}_{10}(t=$ 2.00; $p<0.0315)$ and trace interval $(t=$ $2.45 ; p<0.013$ ) within the left medial thalamus. In addition, medial thalamic activity showed learning-related changes within the first block of training. A significant main effect for stimulus period (right: $F_{(3,48)}=14.13, p<0.002$; left: $\left.F_{(3,48)}=12.15, p<0.003\right)$ and a stimulus period by trial interaction (right: $F_{(12,192)}$ $=9.48, p<0.007$; left: $F_{(12,192)}=6.20, p<$ $0.024)$ were seen during the first training block. Post hoc comparisons showed that responses were similar for the $\mathrm{CS}+$ and CS - on the first trial (right: $t<1.00$; left: $t<1.00$ ) with differences developing between them by the last trial (right: $t=3.37$, $p<0.002$; left: $t=2.28, p<0.0185$ ).

Post hoc comparisons of supramarginal gyrus data showed larger responses during the CS+ $(t=5.18 ; p<0.0001), \mathrm{CS}_{10}(t=$ 3.77; $p<0.001)$, and trace interval $(t=$ 3.88; $p<0.0005)$ compared with CS - trials. No other differences were observed.

In summary, delay and trace conditioning trials evoked a larger response than $\mathrm{CS}$ - trials within the AC, bilateral medial thalamus, and left supramarginal gyrus. Within the AC and medial thalamus, similar responses were initially evoked by all conditioned stimuli; however, with repeated training, larger responses developed to presentations of the delay and trace stimuli compared with the CS-.

Trace interval activity

ROIs in which the AUC was greater during the trace interval than to other stimulus periods $\left(\mathrm{CS}+, \mathrm{CS}-\right.$, and $\left.\mathrm{CS}_{10}\right)$ include bilateral middle frontal gyri (right: $F_{(3,48)}=$ 16.40, $p<0.001$; left: $F_{(3,48)}=22.70, p<$ $0.0001)$, supplementary motor area $\left(F_{(3,48)}\right.$ $=20.73 ; p<0.0001)$, bilateral frontal operculum (right: $F_{(3,48)}=31.22, p<$ 0.0001 ; left: $\left.F_{(3,48)}=38.75, p<0.0001\right)$, and right inferior parietal lobule $\left(F_{(3,48)}=\right.$ 17.85, $p<0.001$ ) (Fig. $2 B$ ). The average fMRI time courses for trace, delay, and $\mathrm{CS}-$ responses within these ROIs are presented in Figure 4.

The magnitude of middle frontal gyrus (MFG) responses was orderly such that the largest responses were evoked during the trace interval compared with the CS - (right: $t=4.72, p<$ 0.0001 ; left: $t=4.41, p<0.0001)$, CS + (right: $t=3.73, p<0.001$; left: $t=1.77, p<0.048$ ), and $\mathrm{CS}_{10}$ (right: $t=3.03, p<0.004$; left:

B CS- presentations.

\section{A Activation related to forming CS-UCS association}
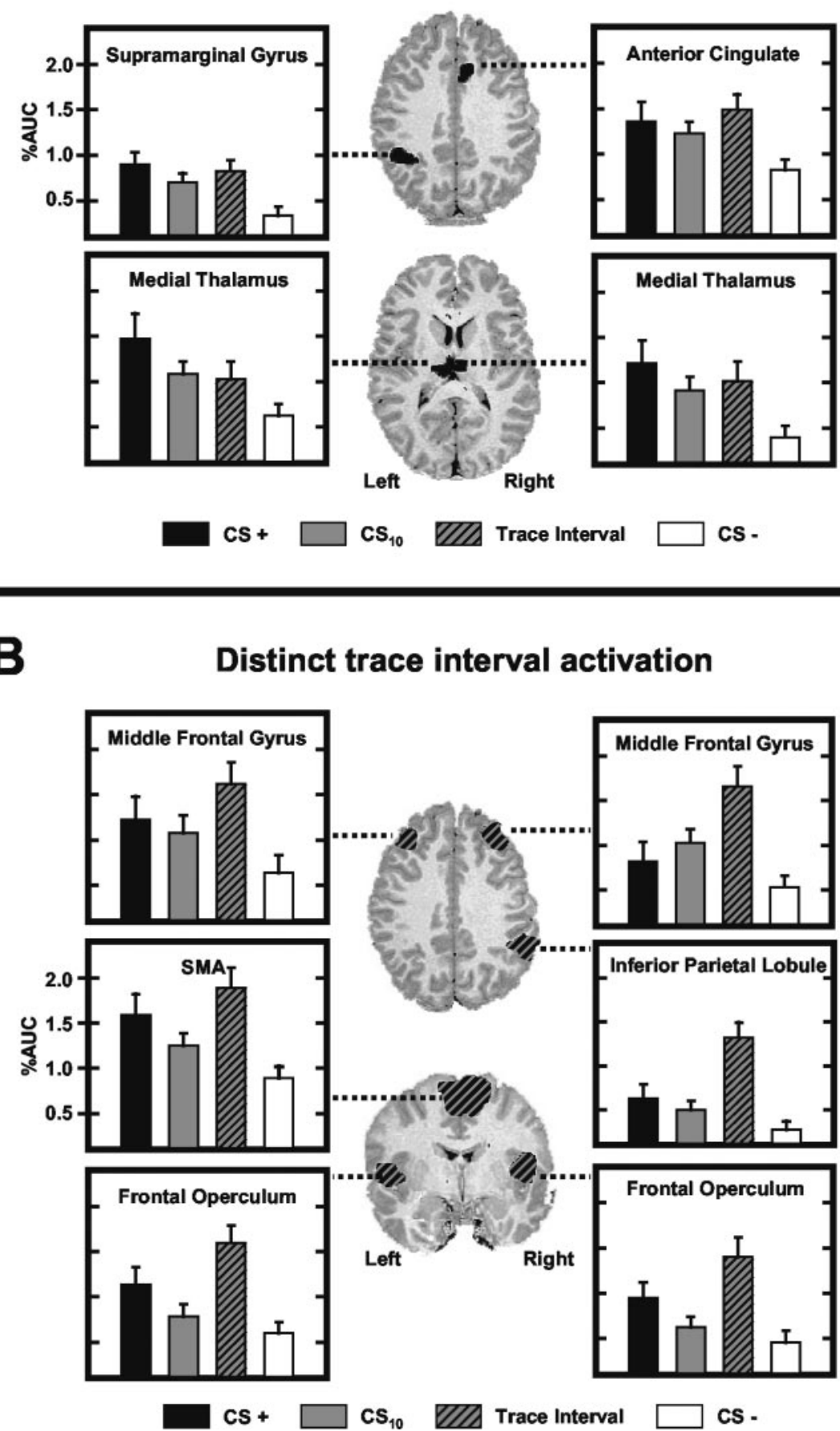

Figure 2. Regional activation during delay and trace conditioning. A, Activation related to forming CS-UCS associations. Histograms depicting the AUC (baseline adjusted area under the impulse response curve) measured for each stimulus (CS + : black; $\mathrm{CS}_{10}$ : solid gray; trace interval: gray and black; $\mathrm{CS}-$ : white) within these ROls are presented. The response magnitude within these regions was significantly larger during the $C S+$ and trace interval than during $C S$ - presentations. $B$, Activation unique to the trace interval. The response magnitude within these regions was larger during the trace interval than during $C S+, C S_{10}$, and

$t=3.11, p<0.004)$, whereas intermediate level responses were elicited by the CS + (right: $t=1.86, p<0.041$; left: $t=4.12, p<$ 0.0005 ) and $\mathrm{CS}_{10}$ (right: $t=3.24, p<0.003$; left: $t=3.08, p<$ $0.004)$ compared with the CS - . Responses elicited by the CS+ were greater within the left than right MFG $(t=2.68 ; p<0.016)$. A significant stimulus period by block interaction (right: $F_{(9,144)}$ 

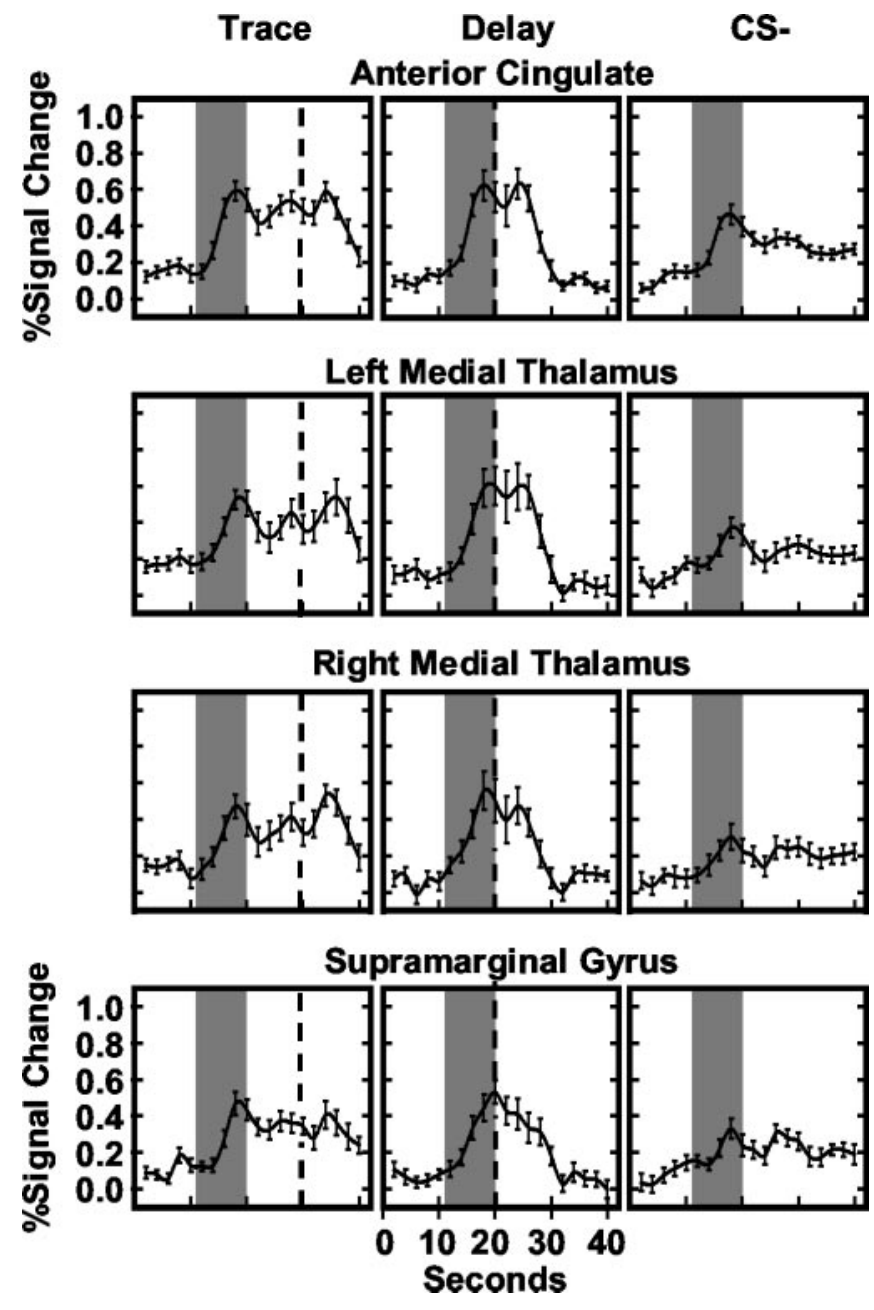

Figure 3. Averaged hemodynamic responses for ROls involved in conditioned responding. The average fMRI time courses for trace, delay, and CS - trials are presented. Gray bars reflect CS presentation, and black dashed line depicts UCS presentation.

$=6.48, p<0.022$; left: $\left.F_{(9,144)}=5.19, p<0.037\right)$ was observed such that differences in right MFG response amplitude developed across the training session to the $\mathrm{CS}+$ and $\mathrm{CS}_{10}$ compared with $\mathrm{CS}-$ presentations (Fig. 5). Byblock 4 , responses to the $\mathrm{CS}+(t=$ $1.90 ; p<0.038)$ and $\mathrm{CS}_{10}(t=2.13 ; p<0.025)$ were significantly larger than CS - responses. Similarly, within the left MFG, differences in response amplitude developed across training with presentations of the CS $+(t=1.97 ; p<0.033)$ and trace interval $(t=$ 2.36; $p<0.0155$ ) larger than that seen to the CS - (Fig. 5).

SMA post hoc comparisons demonstrated that larger responses occurred during the trace interval compared with the $\mathrm{CS}-(t=5.39 ; p<0.0001), \mathrm{CS}+(t=2.55 ; p<0.011)$, and $\mathrm{CS}_{10}$ $(t=4.22 ; p<0.0005)$. Intermediate level responses were elicited by the CS $+(t=2.06 ; p<0.028)$ that were greater than $\mathrm{CS}_{10}$ responses, which in turn were larger than CS - responses $(t=$ 3.36; $p<0.002)$. In addition, SMA activation showed learningrelated changes within the first block of training. A significant main effect for stimulus period $\left(F_{(3,48)}=7.85 ; p<0.013\right)$ and a stimulus period by trial interaction $\left(F_{(12,192)}=5.12 ; p<0.038\right)$ were observed on block 1. Post hoc t test comparisons showed that the responses to the CS + and CS - were not different on the first trial. Over the remainder of block 1 , however, evoked responses were larger during the CS $+(t=3.84 ; p<0.0005)$ than CS - .

Post hoc comparisons of frontal operculum activity revealed

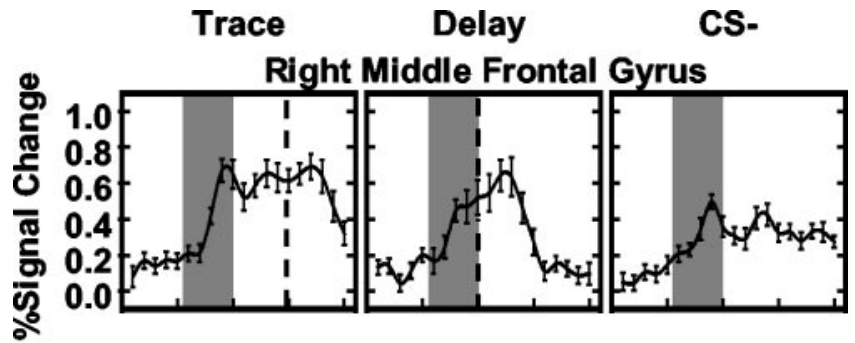

Left Middle Frontal Gyrus

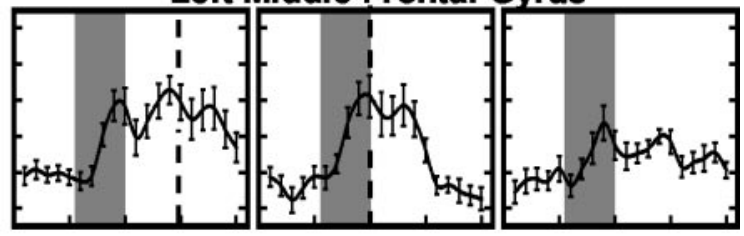

Supplementary Motor Area

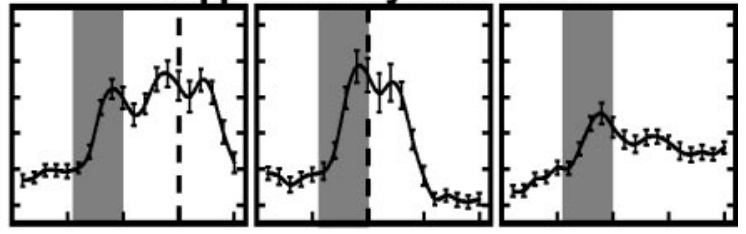

Inferior Parietal Lobule

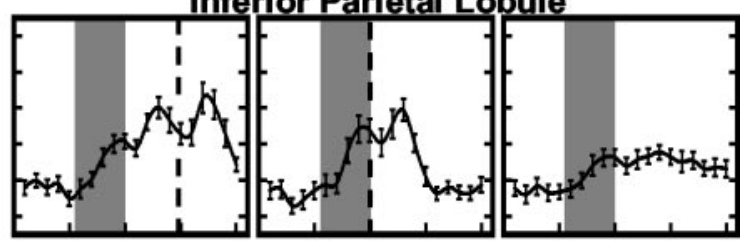

Right Frontal Operculum
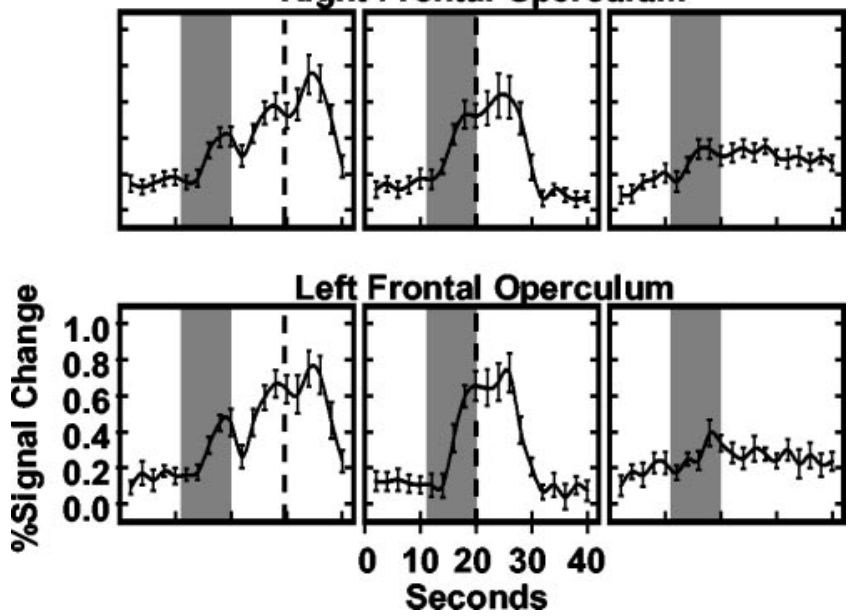

Figure 4. Averaged hemodynamic responses for ROls mediating trace interval processes. The average fMRI time courses for trace, delay, and $\mathrm{CS}$ - trials are presented. Gray bars reflect CS presentation, and black dashed line depicts UCS presentation.

larger responses during the trace interval compared with the CS - (right: $t=5.23, p<0.0001$; left: $t=5.11, p<0.0001$ ), CS + (right: $t=2.55, p<0.011$; left: $t=2.31, p<0.018$ ), and $\mathrm{CS}_{10}$ (right: $t=5.03, p<0.0001$; left: $t=5.03, p<0.0001$ ), with an intermediate response level to the CS + that was greater than that to the CS(right: $t=4.12, p<0.0005$; left: $t=3.48, p<0.0015$ ) and $\mathrm{CS}_{10}$ (right: $t=1.79, p<0.0005$; left: $t=2.05, p<0.0285$ ). No differences in response amplitude were observed between the left and right frontal operculum. 
Post hoc comparisons of the right inferior parietal activity showed larger responses during the trace interval compared with the CS $-(t=4.81 ; p<0.0001)$, $\mathrm{CS}+(t=4.09 ; p<0.0005)$, and $\mathrm{CS}_{10}(t=$ 5.47; $p<0.0001)$. Intermediate levels of responding were observed for the CS+ and $\mathrm{CS}_{10}$. These responses were smaller than trace interval responses but larger than $\mathrm{CS}-$ responses $(\mathrm{CS}+: t=2.19, p<$ 0.0215; $\left.\mathrm{CS}_{10}: t=1.75, p<0.05\right)$.

In summary, trace interval responses were larger than the responses elicited by all other stimulus periods within the bilateral MFG, SMA, bilateral frontal operculum, and right inferior parietal lobule. Within the bilateral MFG and SMA, similar responses were evoked initially by all conditioned stimuli; however, with repeated training, differential responses developed within these regions.

\section{Deactivation}

Several regions showed task-induced changes in fMRI signal intensity that fell below baseline levels during delay or trace conditioning, whereas relatively little change from baseline was observed during CStrials (Table 2, Fig. 6). These task-induced decreases in BOLD signal tended to develop across training blocks and were observed within the anterior (main effect: $F_{(3,48)}=$ 20.79, $p<0.003$; interaction: $\left.F_{(9,144)}=7.34, p<0.015\right)$ and posterior cingulate (main effect: $F_{(3,48)}=32.22, p<0.0001$; interaction: $\left.F_{(9,144)}=8.23, p<0.011\right)$, left superior frontal (main effect: $F_{(3,48)}=17.10, p<0.001$; interaction: $F_{(9,144)}=6.17, p<$ 0.024 ), left superior temporal (main effect: $F_{(3,48)}=13.51, p<$ 0.002; interaction: $\left.F_{(9,144)}=16.51, p<0.001\right)$, middle temporal (main effect: $F_{(3,48)}=18.54, p<0.001$; interaction: $F_{(9,144)}=$ 22.94, $p<0.0001$ ), left inferior frontal (main effect: $F_{(3,48)}=$ 15.44, $p<0.001$ ), and right postcentral gyri (main effect: $\left.F_{(3,48)}=19.09, p<0.0001\right)$.

Significantly more deactivation was observed within the AC during the trace interval than in response to $\mathrm{CS}+(t=3.63$; $p<$ $0.001), \mathrm{CS}_{10}(t=4.89 ; p<0.0001)$, and $\mathrm{CS}-(t=4.53 ; p<$ $0.0001)$ presentations. The $\mathrm{CS}_{10}$, trace interval, and CS - evoked similar responses on block 1; however, large differences were evident between comparisons of the trace interval with the CS$(t=4.06 ; p<0.0005)$ and $\mathrm{CS}_{10}(t=4.62 ; p<0.0001)$ by block 4 (Fig. 6).

Post hoc comparisons of posterior cingulate activity demonstrated more deactivation during the trace interval compared with the CS $+(t=5.89 ; p<0.0001), \mathrm{CS}_{10}(t=6.43 ; p<0.0001)$, and CS $-(t=5.77 ; p<0.0001)$. These differences were present on all training blocks. In addition, a significant stimulus period by block interaction $\left(F_{(3,144)}=8.23 ; p<0.011\right)$ was demonstrated with similar responses to the CS + and CS - on block 1 , and subtle but significantly more deactivation during CS + compared with $\mathrm{CS}-(t=1.77 ; p<0.048)$ trials on block 4 (Fig. 6).

Left superior frontal gyrus comparisons demonstrated more deactivation during the trace interval compared with the CS+ $(t=3.31 ; p<0.002), \mathrm{CS}_{10}(t=4.70 ; p<0.0001)$, and CS $-(t=$ $4.55 ; p<0.0001)$. Similar activity was observed on block 1 during the $\mathrm{CS}_{10}$ and trace interval. Over the course of training, trace interval responses decreased below baseline such that significant differences were observed compared with the $\mathrm{CS}_{10}(t=4.16 ; p<$ $0.0005)$ on block 4 . In addition, response differences developed among the $\mathrm{CS}+, \mathrm{CS}_{10}$, and $\mathrm{CS}-$ across training with similar activity on block 1 and significantly greater deactivation elicited by the CS + compared with the $\mathrm{CS}_{10}(t=2.38 ; p<0.015)$ and CS $-(t=2.82 ; p<0.006)$ on block 4 .

The pattern of left superior temporal gyrus activity was orderly such that more deactivation was observed during the trace interval than during CS $+(t=3.39 ; p<0.002), \mathrm{CS}_{10}(t=3.31$; $p<0.002)$, and CS $-(t=4.16 ; p<0.0005)$ presentations. An intermediate level of deactivation was elicited by the CS $+(t=$ $3.76 ; p<0.001)$ and $\mathrm{CS}_{10}(t=2.24 ; p<0.0195)$ compared with the CS - . Similar activity was observed during all stimulus periods on block 1 , whereas CS $+\left(\mathrm{CS}-: t=4.24, p<0.0005\right.$ CS $_{10}$ : $t=3.12, p<0.0035)$ and trace interval (CS-: $t=4.18, p<$ 0.0005 CS $_{10}: t=3.69, p<0.001$ ) deactivation differed from the signal measured during the $\mathrm{CS}-$ and $\mathrm{CS}_{10}$ on block 4 (Fig. 6).

Post hoc comparisons of right middle temporal gyrus activity showed significantly more trace interval deactivation compared with CS $+(t=4.52 ; p<0.0001), \mathrm{CS}_{10}(t=4.10 ; p<0.0005)$, and $\mathrm{CS}-(t=4.98 ; p<0.0001)$ responses. Similar responses were observed during all stimulus periods on block 1 ; however, differences developed over training such that more deactivation was observed during the CS $+\left(\mathrm{CS}-: t=3.52, p<0.0015 \mathrm{CS}_{10}: t=\right.$ 2.42, $p<0.014)$ and trace interval (CS $-: t=5.19, p<0.0001$; $\left.\mathrm{CS}_{10}: t=3.79, p<0.001\right)$ compared with the $\mathrm{CS}-$ and $\mathrm{CS}_{10}$ on block 4 (Fig. 6).

Post hoc comparisons of left inferior frontal and right postcentral gyrus activity showed more deactivation during the trace interval than during the CS + (inferior frontal: $t=3.34, p<$ 0.002; postcentral: $t=5.18, p<0.0001$ ), $\mathrm{CS}_{10}$ (inferior frontal: $t=5.44, p<0.0001$; postcentral: $t=5.10, p<0.0001)$, and CS (inferior frontal: $t=3.12, p<0.0035$; postcentral: $t=4.10, p<$ $0.0005)$. In addition, left inferior frontal gyrus AUC was greater during presentations of the $\mathrm{CS}_{10}$ than $\mathrm{CS}-(t=2.06$; $p<$ $0.0285)$.

In summary, deactivations were observed within superior frontal, inferior frontal, superior temporal, middle temporal, 

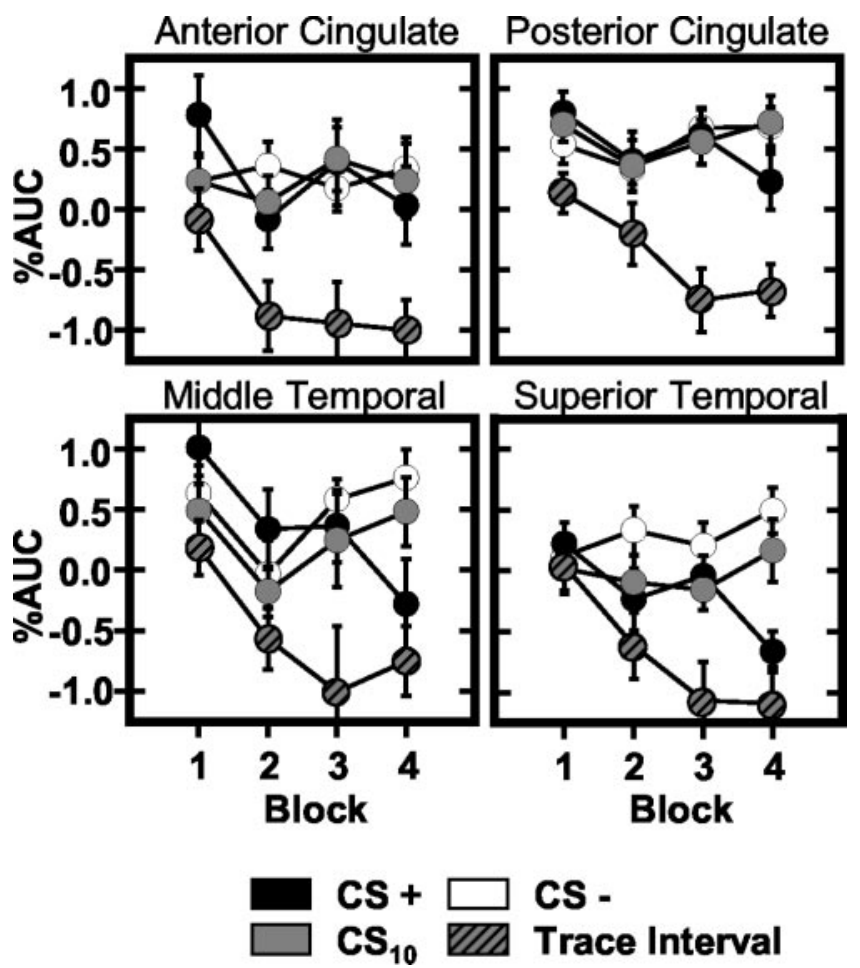

Figure 6. Regions showing task-induced deactivations during training. Graphs reflect the AUC (baseline adjusted area under the impulse response curve) measured for each stimulus $\left(\mathrm{CS}+\right.$ : black; $\mathrm{CS}_{10}$ : solid gray; trace interval: gray and black; $\mathrm{CS}-$ : white) during the four blocks of training.

postcentral, anterior cingulate, and posterior cingulate gyri during delay or trace conditioning but not during CS - trials. Deactivation in many of these regions has been observed previously (Shulman et al., 1997; Binder et al., 1999; Gusnard and Raichle, 2001). One popular interpretation of such deactivation is that processes that occur during the intertrial interval are interrupted by task performance (Binder et al., 1999). It follows that to the degree that resting state processes are inhibited by task demands, lower resting state signal should be observed early in training when subjects are learning the relationships between conditioned and unconditioned stimuli. That is, early in training, subjects are not aware of the relationships between CSs and the UCS and therefore are actively engaged in the semantic processes that interfere with resting state activity. As subjects learn the CS-UCS relationships the task becomes less ambiguous, and resting state activity in these regions is expected to increase. Task performance during delay and trace trials would continue to interfere with resting state activation, however, driving a decrease in regional activity below baseline levels. In most cases, task performance is minimal on CS - trials and therefore is less likely to interfere with resting state activity. Consistent with this hypothesis, the deactivation developed across training within the present study as the task became easier.

\section{Hippocampus}

Task-induced decreases in BOLD signal on trace conditioning trials were also observed within the left hippocampus $\left(F_{(3,48)}=\right.$ 19.09; $p<0.0001)$. This region showed CS-evoked changes in fMRI signal intensity that fell below baseline values and differed significantly from the signal measured on CS - trials. Furthermore, a significantly greater decrease in fMRI signal was observed during the trace interval compared with the CS $(t=3.53 ; p<$
A Hippocampus

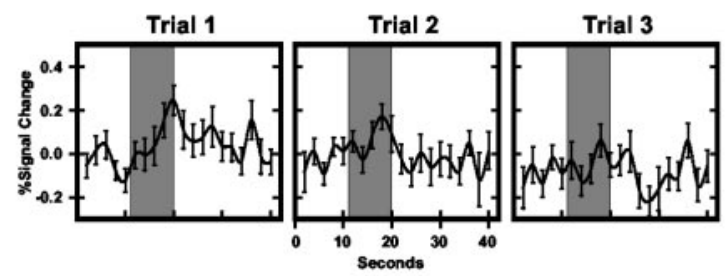

B

C

\section{Shock Expectancy}
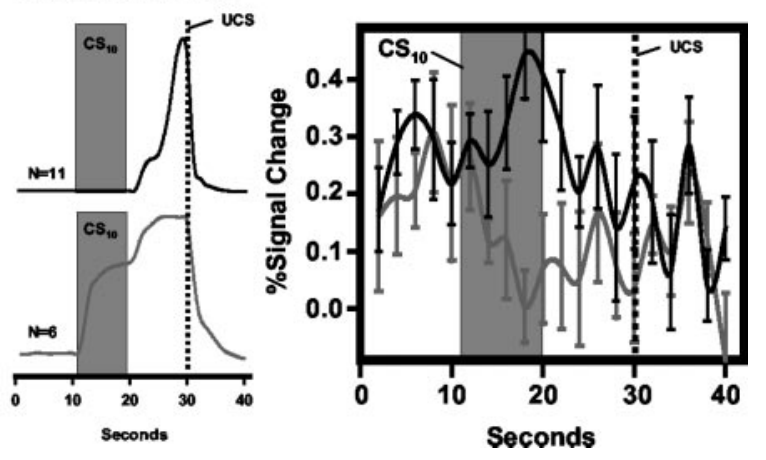

Figure 7. Hippocampal and shock expectancy responses during trace conditioning. A, Average left hippocampal evoked response for all conditioned stimuli (delay, trace, and CS - ) on the first three conditioning trials. Response magnitude gradually declined across the first block of training. $B, C$, Average shock expectancy $(B)$ for subjects that precisely $(n=11)$ and imprecisely $(n=6)$ timed UCS presentation on trace conditioning trials, and corresponding hippocampal activation ( () for these groups. Black lines reflect shock expectancy and hippocampal activity of precise estimators; gray lines depict that of imprecise estimators. \%Signal Change $=$ baseline adjusted impulse response function.

$0.0015), \mathrm{CS}_{10}(t=3.71 ; p<0.001)$, and CS $-(t=3.50 ; p<$ $0.0015)$. This pattern of hippocampal activity developed over the course of training. In fact, early in training, a significant increase in activity was observed during presentations of each conditional stimulus type. These responses decreased over the first three trials of block 1 (Fig. 7A), such that a significant decrease in BOLD signal was observed on subsequent trial blocks.

An additional analysis comparing hippocampal activity with SE revealed that although all subjects were aware of the CS-UCS relationships by the end of training, the timing of subjects' SE responses varied on trace conditioning trials. Six subjects showed increased SE during the $\mathrm{CS}_{10}$ (imprecise estimators of UCS), although 11 subjects showed increased SE only during the trace interval (precise estimators). Shock expectancies ranged from 0 to 6 (mean $=0.76 \pm 0.56)$ for precise estimators and from 32 to $100($ mean $=69.67 \pm 10.24)$ for imprecise estimators during the $\mathrm{CS}_{10}$, whereas SE was $>90($ mean $=94.54 \pm 3.24)$ for all subjects during the trace interval (Fig. $7 B$ ). Comparisons of precise and imprecise estimators of UCS presentation showed larger hippocampal responses during $\mathrm{CS}_{10}$ trials for precise estimators on block 1 of training $(t=1.88 ; p<0.04)$ (Fig. $7 C)$. These groups did not differ in the intensity of the electrical stimulation received (precise: $2.40 \pm 0.94 \mathrm{~mA}$; imprecise: $3.58 \pm 0.82$ ) or in their subjective pain ratings (precise: $4.17 \pm 0.25$; imprecise: $3.77 \pm$ $0.31)$.

\section{Discussion}

Delay and trace activity

Regions related to delay and trace CRs include the AC, medial thalamus, and left supramarginal gyrus. Similar learning-related 
changes have been demonstrated previously within the AC and medial thalamus (Buchel et al., 1998, 1999; LaBar et al., 1998; Knight et al., 1999). AC responses on delay and trace trials increased with repeated UCS pairings, whereas responses to the CS - remained small. The AC has been implicated in anticipation, pain, attention, emotion, and error detection. Our results do not appear to be related to error detection or performance monitoring (Carter et al., 1998; MacDonald et al., 2000), because activation was smaller during trials in which the appropriate response was less clear (i.e., the beginning of training) and increased as training progressed and the appropriate response became apparent. Similarly, our results cannot be attributed to pain-related activity. We selected portions of the time course before UCS presentations for analysis to exclude pain or unconditional responding. In addition, these AC results cannot be adequately explained by its proposed modulatory role in internal emotional states and autonomic activity (Vogt et al., 1979; Yeterian and Pandya, 1988; Devinsky et al., 1995). AC response magnitude increased across training, whereas SCR magnitude and pain estimates tended to decrease, indicating a negative relationship between these measures. In contrast, our results are consistent with theories suggesting that Pavlovian learning is related to anticipation or attentional processes (Pearce and Hall, 1980; Mackintosh, 1983). The largest AC responses were observed during the CS+ and trace interval, just before UCS presentations, which is consistent with demonstrations of increased AC blood flow with anticipation (Posner et al., 1988; Paus et al., 1993).

Learning-related changes observed within bilateral medial thalamus developed quickly and then diminished progressively over the remainder of training. The event-related time course was similar to that observed within the AC, which is not surprising given its efferent projections to AC cortex (Devinsky et al., 1995; Craig, 2003). There are also prominent medial thalamic connections with insular, prefrontal, and medial temporal areas, supporting suggestions that this region plays an important role in memory (Vogt et al., 1979; Russchen et al., 1987; Ongur and Price, 2000; Craig, 2003). Medial thalamic damage produces amnesia in humans (Brown et al., 1989), and animal lesion studies show disruption of working and reference memory (Markowitsch, 1982; Zola-Morgan and Squire, 1985; Stokes and Best, 1990; Hunt and Aggleton, 1991).

In the present study, we did not observe changes in amygdala activity, although this region is known to be important for conditional fear (Helmstetter and Bellgowan, 1994; LeDoux, 1995; Davis, 2000). Although most of the research exploring the contribution of the amygdala to conditional fear has been conducted in laboratory animals, a number of studies with humans have been performed (Bechara et al., 1995; Buchel et al., 1998; LaBar et al., 1998; Cheng et al., 2003). Although several have demonstrated amygdala metabolic activation during fear conditioning and related procedures (Buchel et al., 1998; LaBar et al., 1998), in other work we have typically not observed similar results when brain activity is related to CS presentations (Knight et al., 1999; Cheng et al., 2003). In contrast, our studies have shown clear learning-related effects by examining similarities between amygdala activity and autonomic CR properties [for a more extensive discussion of this issue, see Cheng et al. (2003)]. Although it is also possible that the present lack of amygdala results may be partially attributable to difficulties with the signal-to-noise ratio within this region at higher field strengths, these results replicate previous studies from our laboratory in that no learning-related amygdala activation was observed when compared with temporal properties of presented stimuli (i.e., using a CS reference wave- form), and preliminary results from a separate detailed analysis of these data show a significant relationship between amygdala activation and conditioned SCRs (Cheng et al., 2001) similar to what we have reported elsewhere (Cheng et al., 2003).

\section{Trace interval activity}

ROIs in which responses were greater during the trace interval compared with other stimulus periods $\left(\mathrm{CS}+, \mathrm{CS}-\right.$, and $\mathrm{CS}_{10}$ ) appear to mediate trace processes. This pattern was observed in bilateral MFG, SMA, bilateral frontal operculum, and right inferior parietal lobule. Many of these regions support working memory processes. Working memory refers to a "limited capacity system for the simultaneous storage and processing of information used to guide behavior in the absence of environmental cues" (Baddeley, 1992). Within many of these regions, intermediate level responses were observed during CS+ presentations, consistent with studies demonstrating activation that is positively correlated with working memory load (Braver et al., 1997; Jonides et al., 1997; Manoach et al., 1997). As such, differences in response magnitude may reflect differences in the working memory load required of delay and trace trials. Because trace trials have an additional $10 \mathrm{sec}$ trace interval not found on delay trials, the working memory load is likely larger for trace than delay. Therefore, larger response magnitudes might be expected during trace trials. Additionally, response selection similar to that required to rate UCS expectancy in the present study may engage frontoparietal networks (Schumacher and D'Esposito, 2002). Although the present study was not designed to identify the precise role that these structures play in trace conditioning, they are likely involved in maintaining a representation of the CS-UCS association during the trace interval and may be involved in the selection and timing of behavioral responses. The medial prefrontal cortex appears to be critical for trace eyeblink CRs in rabbits (Weible et al., 2000), and studies support the involvement of prefrontal and parietal regions in human working memory (Paulesu et al., 1993; Gathercole, 1994; Jonides et al., 1997; Tsukiura et al., 2001). The SMA and frontal operculum may code timing information (Schubotz and von Cramon, 2001). The SMA has been associated with self-generated movement (Goldberg, 1985), whereas frontal operculum activity has been demonstrated when a sensory event is timed or anticipated as well as when movement is synchronized to a sensory event (Platel et al., 1997; Rao et al., 1997; Schubotz et al., 2000). Buchel et al. (1999) reported dorsolateral prefrontal cortex and anterior insula activation during trace conditioning. The coordinates of the activation that they observed are near the MFG and frontal operculum activations in the current study. Given the controls used, these authors were unable to determine whether the activity was generally related to forming CS-UCS associations or trace-specific processing. In our study, however, MFG and frontal oppercular responses were larger during the trace interval compared with all other stimulus periods, providing a clear link to trace interval processes.

\section{Hippocampus}

A number of roles have been proposed for the hippocampus in trace conditioning, including "bridging the temporal gap," coding temporal information, and supporting awareness of stimulus relationships that may be necessary for trace, but not delay, conditioning. Hippocampal results here did not show increased trace interval activity, as would be expected if its role was bridging the gap between CS and UCS. All subjects demonstrated awareness of CS-UCS relationships by the end of training, preventing a direct 
comparison of aware versus unaware participants; however, timing differences were present in subjects' SE responses on trace trials. Precise estimators demonstrated increased SE only during the trace interval, whereas imprecise estimators showed an increase in SE during the $\mathrm{CS}_{10}$ and trace interval. Group comparisons revealed larger hippocampal responses for precise than imprecise estimators during the $\mathrm{CS}_{10}$ on block 1 . Similar differences were not demonstrated for the $\mathrm{CS}+$ or $\mathrm{CS}-$. These results suggest that the hippocampus may play a time-limited role in learning the timing of this response. Similar time-limited hippocampal activation during trace conditioning has been reported previously (Buchel et al., 1999). Nevertheless, there are substantial differences between the hippocampal results and conclusions of the present study compared with those of Buchel et al. (1999). Specifically, the time-limited evoked responses in the present study were similar for all conditioned stimuli, whereas Buchel et al. (1999) observed this effect on trace but not CS - trials. They included unpaired preconditioning trials before the training session, leaving stimulus pre-exposure and contingency shifts as potential confounds. Time-limited hippocampal activation for all stimuli, as demonstrated in the present study, is consistent with previous studies showing hippocampal activity with novel stimulus presentations (Stern et al., 1996).

Although the results of the present study provide new insights into the neural substrates mediating delay and trace fear conditioning, a number of questions remain. First, this study used a discrimination procedure leaving unanswered the questions regarding brain activity evoked by simple delay and trace procedures. Discrimination paradigms likely recruit brain regions that are not typically active during fear conditioning to a single CS. A second question relates to the influence of the duration of time between CS onset and UCS presentation. In the present study, delay and trace conditioning trials differed not only in the presence of the trace interval but also in the duration of time between CS onset and UCS presentation. The present analysis focused on activity specific to the trace interval; however, varying the duration of time from CS onset to UCS presentation may differentially affect activity within these regions. The impact of such manipulations should be addressed in future studies.

\section{Conclusions}

The primary goal of the present study was to examine the neurobiological substrates of human delay and trace fear conditioning. SCR and contingency awareness recorded concurrently with brain imaging data confirmed that the present paradigm supports Pavlovian conditioning. Significant activation was observed within the visual cortex for all CSs. Anterior cingulate and medial thalamic activity reflected associative learning common to both delay and trace conditioning, whereas SMA, frontal operculum, middle frontal, and inferior parietal activations were associated specifically with trace interval processing. The hippocampus appears to code temporal information only during trace conditioning. These results demonstrate overlapping patterns of activation within the anterior cingulate, medial thalamus, and visual cortex during delay and trace procedures, with additional recruitment of the hippocampus, SMA, frontal operculum, middle frontal gyri, and inferior parietal lobule during trace conditioning. These data suggest that the hippocampus codes temporal information during trace conditioning, whereas brain regions supporting working memory processes maintain the CS-UCS representation during the trace interval.

\section{References}

Baddeley AD (1992) Working memory. Science 255:556-559.

Bechara A, Tranel D, Damasio H, Adolphs R, Rockland C, Damasio A (1995) Double dissociation of conditioning and declarative knowledge relative to the amygdala and hippocampus in humans. Science 269:1115-1118.

Berger TY, Rinaldi PC, Weisz DJ, Thompson RF (1983) Single-unit analysis of different hippocampal cell types during classical conditioning of rabbit nictitating membrane response. J Neurophysiol 50:1197-1219.

Binder JR, Frost JA, Hammeke TA, Bellgowan PSF (1999) Conceptual processing during the conscious resting state: a functional MRI study. J Cognit Neurosci 11:80-93.

Braver TS, Cohen JD, Nystrom LE, Jonides J, Smith EE, Noll DC (1997) A parametric study of prefrontal cortex involvement in human working memory. NeuroImage 5:49-62.

Brown GG, Kieran S, Patel S (1989) Memory functioning following a left medial thalamic hematoma. J Clin Exp Neuropsychol 11:206-218.

Buchel C, Morris J, Dolan RJ, Friston KJ (1998) Brain systems mediating aversive conditioning: an even-related fMRI study. Neuron 20:947-957.

Buchel C, Dolan RJ, Armony JL, Friston KJ (1999) Amygdala-hippocampal involvement in human aversive trace conditioning revealed through event-related functional magnetic resonance imaging. J Neurosci 19:10869-10876.

Carter CS, Braver TS, Barch DM, Botvinick MM, Noll D, Cohen JD (1998) Anterior cingulate cortex, error detection, and the online monitoring of performance. Science 280:747-749.

Carter RM, Hofstotter C, Tsuchiya N, Koch C (2003) Working memory and fear conditioning. Proc Natl Acad Sci USA 100:1399-1404.

Cheng DT, Knight DC, Smith CN, Stein EA, Helmstetter FJ (2001) Eventrelated FMRI of neural substrates important for learned responses during Pavlovian fear conditioning. Soc Neurosci Abstr 27:75.3.

Cheng DT, Knight DC, Smith CN, Stein EA, Helmstetter FJ (2003) Functional MRI of human amygdala activity during Pavlovian fear conditioning: stimulus processing versus response expression. Behav Neurosci $117: 3-10$

Clark RE, Squire LR (1998) Classical conditioning and brain systems: the role of awareness. Science 280:77-81.

Cole RP, Barnet RC, Miller RR (1995) Temporal encoding in trace conditioning. Anim Learn Behav 23:144-153.

Cox RW, Hyde JS (1997) Software tools for the analysis and visualization of fMRI data. NMR Biomed 10:171-178.

Cox RW, Jesmanowicz A (1999) Real-time 3D image registration for functional MRI. Magn Reson Med 42:1014-1018.

Craig AD (2003) Pain mechanisms: labeled lines versus convergence in central processing. Annu Rev Neurosci 26:1-30.

Davis M (2000) The role of the amygdala in conditioned and unconditioned fear and anxiety. In: The amygdala: a functional analysis (Aggleton JP, ed), pp 213-287. New York: Oxford UP.

Devinsky O, Morrell MJ, Vogt BA (1995) Contributions of anterior cingulate cortex to behaviour. Brain 118:279-306.

Gathercole SE (1994) Neuropsychology and working memory: a review. Neuropsychology 8:494-505.

Goldberg G (1985) Supplementary motor area structure and function: review and hypothesis. Behav Brain Sci 8:567-616.

Gusnard DA, Raichle ME (2001) Searching for a baseline: functional imaging and the resting human brain. Nat Rev Neurosci 2:685-694.

Helmstetter F, Bellgowan P (1994) Effects of muscimol applied to the basolateral amygdala on acquisition and expression of contextual fear conditioning in rats. Behav Neurosci 108:1005-1009.

Hugdahl K, Berardi A, Thompson W, Kosslyn S, Macy R, Baker D, Alpert N, LeDoux J (1995) Brain mechanisms in human classical conditioning: a PET blood flow study. NeuroReport 6:1723-1728.

Hunt PR, Aggleton JP (1991) Medial dorsal thalamic lesions and working memory in the rat. Electromyog Clin Neurophysiol 55:227-246.

James GO, Jardiman MJ, Yeo CH (1987) Hippocampal lesions and trace conditioning in the rabbit. Behav Brain Res 23:109-116.

Jonides, J. Schumacher EH, Smith EE, Lauber EJ, Awh E (1997) Verbal working memory load affects regional brain activation as measured by PET. J Cognit Neurosci 9:462-475.

Knight DC, Smith CN, Stein EA, Helmstetter FJ (1999) Functional MRI of human Pavlovian fear conditioning: patterns of activation as a function of learning. NeuroReport 10:3665-3670. 
LaBar KS, Disterhoft JF (1998) Conditioning, awareness, and the hippocampus. Hippocampus 8:620-626.

LaBar KS, Gatenby JC, Gore JC, LeDoux JE, Phelps EA (1998) Human amygdala activation during conditioned fear acquisition and extinction: a mixed-trial study. Neuron 20:937-945.

LeDoux JE (1995) Emotion: clues from the brain. Annu Rev Psychol 46:209-235.

LeDoux JE (2000) Emotion circuits in the brain. Annu Rev Neurosci 23:155-184.

Lovibond PF, Shanks DR (2002) The role of awareness in Pavlovian conditioning: empirical evidence and theoretical implications. J Exp Psychol Anim Behav Process 28:3-26.

MacDonald AW, Cohen JD, Stenger VA, Carter CS (2000) Dissociating the role of the dorsolateral prefrontal and anterior cingulate cortex in cognitive control. Science 288:1835-1838.

Mackintosh N (1983) Conditioning and associative learning. New York: Oxford UP.

Manoach DS, Schlaug G, Siewert B, Darby DG, Bly BM, Benfield A, Edeiman RR, Warach S (1997) Prefrontal cortex fMRI signal changes are correlated with working memory load. NeuroReport 8:545-549.

Maren S (2001) Neurobiology of Pavlovian fear conditioning. Annu Rev Neurosci 24:897-931.

Markowitsch HJ (1982) Thalamic mediodorsal nucleus and memory: a critical evaluation of studies in animals and man. Neurosci Biobehav Rev 6:351-380.

McEchron MD, Bouwmeester H, Tseng W, Weiss C, Disterhoft JF (1997) Hippocampectomy disrupts auditory trace fear conditioning and contextual fear conditioning in the rat. Hippocampus 8:638-646.

McEchron MD, Bouwmeester H, Tseng W, Weiss C, Disterhoft JF (1998) Hippocampectomy disrupts auditory trace fear conditioning and contextual fear conditioning in the rat. Hippocampus 8:638-646.

McGlinchey-Berroth R, Carrillo MC, Gabrieli JD, Brawn CM, Disterhoft JF (1997) Impaired trace eyeblink conditioning in bilateral, medialtemporal lobe amnesia. Behav Neurosci 111:873-882.

Moyer JR, Deyo RA, Disterhoft JF (1990) Hippocampectomy disrupts trace eye-blink conditioning in rabbits. Behav Neurosci 104:243-252.

Ongur D, Price JL (2000) The organization of networks within the orbital and medial prefrontal cortex of rats, monkeys, and humans. Cereb Cortex 10:206-219.

Paulesu E, Frith CD, Frackowiak RSJ (1993) The neuronal correlates of the verbal component of working memory. Nature 362:342-343.

Paus T, Petides M, Evans A, Meyer E (1993) Role of the human anterior cingulate cortex in the control of oculomotor, manual, and speech responses: a positron emission tomography study. J Neurophysiol 70:453-469.

Pearce J, Hall G (1980) A model for Pavlovian learning: variations in the effectiveness of conditioned but not unconditioned stimuli. Psychol Rev 106:532-552.

Platel H, Price C, Baron J, Wise R, Lambert J, Frackowiak RSJ, Lechevalier B, Eustache F (1997) The structural components of music perception: a functional anatomical study. Brain 120:229-243.

Posner M, Petersen S, Fox P, Raichle M (1988) Localization of cognitive operations in the human brain. Science 240:1627-1631.

Prokasy WF, Raskin DC (1973) Electrodermal activity in psychological research. New York: Academic.

Rao SM, Harrington DL, Haaland KY, Bobholz JA, Cox RW, Binder JR
(1997) Distributed neural systems underlying the timing of movements. J Neurosci 17:5528-5535.

Rescorla R (1988) Behavioral studies of Pavlovian conditioning. Annu Rev Neurosci 11:329-352.

Rodriguez P, Levy WB (2001) A model of hippocampal activity in trace conditioning: where's the trace? Behav Neurosci 115:1224-1238.

Russchen RT, Amaral DG, Price JL (1987) The afferent input to the magnocellular division of the mediodorsal thalamic nucleus in the monkey, Macaca fascicularis. J Comp Neurol 256:175-210.

Schubotz RI, von Cramon DY (2001) Functional organization of the lateral premotor cortex: fMRI reveals different regions activated by anticipation of object properties, location, and speed. Cognit Brain Res 11:97-112.

Schubotz RI, Friederici AD, von Cramon DY (2000) Time perception and motor timing: a common cortical and subcortical basis revealed by fMRI. NeuroImage 11:1-12.

Schumacher EH, D’Esposito M (2002) Neural implementation of response selection in humans as revealed by localized effects of stimulus-response compatibility on brain activation. Hum Brain Mapp 17:193-201.

Shulman GL, Fiez JA, Corbetta M, Buckner RL, Miezin FM, Raichle ME, Petersen SE (1997) Common blood flow changes across visual tasks: II. Decreases in cerebral cortex. J Cognit Neurosci 9:648-663.

Solomon PR, Vander Schaaf ER, Thompson RF, Weisz DJ (1986) Hippocampus and trace conditioning of the rabbit's classically conditioned nictitating membrane response. Behav Neurosci 100:729-744.

Stern CE, Corkin S, Gonzalez RG, Guimaraes AR, Baker JR, Jennings PJ, Carr CA, Sugiura RM, Vedantham V, Rosen BR (1996) The hippocampal formation participates in novel picture encoding: evidence from functional magnetic resonance imaging. Proc Natl Acad Sci USA 93:8660-8665.

Stokes KA, Best PJ (1990) Mediodorsal thalamic lesions impair "reference" and "working" memory in rats. Physiol Behav 47:471-476.

Talairach J, Tournoux P (1988) Co-planar stereotaxic atlas of the human brain: 3-dimensional proportional system: an approach to cerebral imaging. Stuttgart, Germany: Thieme.

Tsukiura T, Fujii T, Takahashi T, Xiao R, Inase M, Iijima T, Yamadori A, Okuda J (2001) Neuroanatomical discrimination between manipulating and maintaining processes involved in verbal working memory: a functional MRI study. Cognit Brain Res 11:13-21.

Vogt BA, Rosene DL, Pandya DN (1979) Thalamic and cortical afferents differentiate anterior from posterior cingulate cortex in the monkey. Science 204:1257-1273.

Weible AP, McEchron MD, Disterhoft JF (2000) Cortical involvement in acquisition and extinction of trace eyeblink conditioning. Behav Neurosci 114:1058-1067.

Weiss C, Kronforst-Collins MA, Disterhoft JF (1996) Activity of hippocampal pyramidal neurons during trace eye blink conditioning. Hippocampus 6:192-209.

Wik G, Elbert T, Fredrikson M, Hoke M, Ross B (1996) Magnetic imaging of human classical conditioning. NeuroReport 7:737-740.

Wolter J, Lachnit H (1993) Are anticipatory first and second interval skin conductance responses indicators of predicted aversiveness? Integr Physiol Behav Sci 28:163-166.

Yeterian EH, Pandya DN (1988) Corticothalamic connections of paralimbic regions in the rhesus monkey. J Comp Neurol 269:130-146.

Zola-Morgan S, Squire LR (1985) Amnesia in monkeys after lesions of the mediodorsal nucleus of the thalamus. Ann Neurol 17:558-564. 